\title{
Integrating the markers Pan I and haemoglobin with the genetic linkage map of Atlantic cod (Gadus morhua)
}

\author{
Tudor Borza*, Brent Higgins, Gary Simpson, Sharen Bowman ${ }^{*}$
}

\begin{abstract}
Background: Haemoglobin ( $\mathrm{Hb}$ ) and pantophysin (Pan I) markers have been used intensively in population studies of Atlantic cod (Gadus morhua) and in the analysis of traits such as temperature tolerance, growth characteristics and sexual maturation. We used an Illumina GoldenGate panel and the KASPar SNP genotyping system to analyse SNPs in three Atlantic cod families, one of which was polymorphic at the Hb $\beta 1$ locus, and to generate a genetic linkage map integrating Pan I and multiple Hb loci.

Findings: Data generated allowed the mapping of nine Hb loci, the Pan I locus, and other 122 SNPs onto an existing linkage genetic map for Atlantic cod. Four $\mathrm{Hb}$ genes (i.e. $\alpha 1, \alpha 4, \beta 1$ and $\beta 5$ ) have been mapped on linkage group (LG) 2 while the other five (i.e. $\alpha 2, \alpha 3, \beta 2, \beta 3$ and $\beta 4$ ) were placed on LG18. Pan I was mapped on LG 1 using a newly developed KASPar assay for a SNP variable only in Pan ${ }^{A}$ allelic variants. The new linkage genetic map presented here comprises 1046 SNPs distributed between 23 linkage groups, with a length of 1145.6 CM. A map produced by forcing additional loci, resulting in a reduced goodness-of-fit for mapped markers, allowed the mapping of a total of 1300 SNPs. Finally, we compared our genetic linkage map data with the genetic linkage map data produced by a different group and identified 29 shared SNPs distributed on 10 different linkage groups.

Conclusions: The genetic linkage map presented here incorporates the marker Pan I, together with multiple $\mathrm{Hb}$ loci, and integrates genetic linkage data produced by two different research groups. This represents a useful resource to further explore if Pan I and Hbs or other genes underlie quantitative trait loci (QTL) for temperature sensitivity/tolerance or other phenotypes.
\end{abstract}

\section{Findings}

The Atlantic cod (Gadus morhua) represents one of the most valuable commercial resources for international fisheries [1]. Haemoglobin (Hb), pantophysin (Pan I), and microsatellite markers have been widely used to characterize the genetic diversity of Atlantic cod populations and their dispersal characteristics [2,3]. In addition, $\mathrm{Hb}$ analyses have revealed correlations between allele types and traits such as growth $[2,4]$, water temperature preference [5], age and seasonality of sexual maturation [6] or annual mortality [7]. Similarly, growth rate [8], water temperature, salinity and depth appear to have an effect on Pan I allele frequencies $[2,9,10]$. Recently, a large number of single nucleotide polymorphisms

\footnotetext{
* Correspondence: tborza@genomeatlantic.ca; sbowman@genomeatlantic.ca Genome Atlantic, NRC Institute for Marine Biosciences, Halifax, NS, Canada
}

(SNPs) have been identified [11-13] and two independent genetic linkage maps have been generated $[12,14]$. However, although SNPs have been characterized in both $\mathrm{Hb}[15,16]$ and Pan I $[9,17,18]$, the position of these markers on a linkage map has yet to be determined. To overcome this deficit we used a combination of methods, i.e. a Illumina GoldenGate panel (Illumina Inc.) comprising 1536 SNPs and the KASPar SNP genotyping system (KBioscience, UK) to place these genes onto a genetic linkage map.

\section{Mapping the haemoglobin genes}

We used a curated Illumina GoldenGate panel containing 1536 SNPs [12], including three SNPs identified in the $\mathrm{Hb} \beta 1$ gene, two SNPs specific to the $\mathrm{Hb} \beta 3$ gene and one characteristic for the $\mathrm{Hb} \beta 4$ gene (details in Additional file 1). These SNPs were derived from 
polymorphisms detected by sequencing nine Atlantic cod $\mathrm{Hb}$ genes in the parents and 15 progeny of a family, B30, that was determined to be heterozygous $(1 / 2)$ at the HbI locus [16]. Western Atlantic cod populations are characterized by a low frequency of allele 1 at the HbI locus $[19,20]$. Family B30 was one of the few families heterozygous at this locus produced by the breeding program of Atlantic Cod Genomics and Broodstock Development Project (CGP) [11]; parents and 93 progeny from this family were used to map these loci. Illumina GoldenGate probe design failed for several of the $\mathrm{Hb}$ SNPs, therefore additional $\mathrm{Hb}$ polymorphisms were identified and used to develop assays for the KASPar SNP genotyping system (Additional file 2). A genetic linkage map was constructed using JoinMap 4 [21]. The genotypes for progeny were converted to $\mathrm{CP}$ codes based on parental genotypes and mapping was performed using a LOD cut-off value of 5.0 and Kosambi's mapping function [21]. The 23 linkage groups obtained for family B30 were compared to the linkage groups previously reported by Hubert et al. 2010 [12]; a 1:1 correspondence between linkage groups (LGs) was confirmed and the corresponding LGs were merged (Figures 1, 2, 3; more details about mapping can be found in Hubert et al. 2010 and Additional file 1). The 23 linkage groups observed for family B30 (and those described in Hubert et al. 2010) matches the number of haploid chromosomes reported for the Atlantic cod by Fan and Fox [22]. The combined results from GoldenGate and KASPar assays allowed the mapping of all $\mathrm{Hb}$ genes analysed: Hb genes $\alpha 1, \alpha 4, \beta 1$ and $\beta 5$ were mapped on LG 2 while $\mathrm{Hb}$ genes $\alpha 3$ and $\beta 2, \beta 3$ and $\beta 4$ were mapped on LG 18 (Figures 1 and 3). Sequencing data from the $\mathrm{Hb} \alpha 2$ gene, which was not polymorphic in the B30 family, indicate that this gene is situated immediately adjacent to the $\mathrm{Hb} \beta 3$ gene [23,24]; therefore the cluster of $\mathrm{Hb}$ genes located on LG 18 contains at least five different $\mathrm{Hb}$ genes. The mapping of Atlantic cod $\mathrm{Hb}$ genes is in agreement with other studies on fish and other vertebrates which indicate that $\mathrm{Hb}$ loci are placed on two linkage groups/two different chromosomes $[25,26]$. Allele frequencies at the $\mathrm{Hb} \beta 1$ locus from several North Atlantic cod populations (Additional file 2) were similar to data collected by $\mathrm{Hb}$ allozyme electrophoresis $[19,20]$ suggesting that $\mathrm{Hb} \beta 1$, or other closely linked genes, might underlie QTLs.

\section{Mapping Pan I}

The two main allele variants $\operatorname{Pan} \mathrm{I}^{\mathrm{A}}$ and $\operatorname{Pan} \mathrm{I}^{\mathrm{B}}$ described at the Pan locus can be determined by assessing the polymorphism present at a DraI site located in intron $4[9,17,27]$. However, these alleles have very different frequencies within different Atlantic cod stocks, and all candidate families from the CGP [11] have been determined to be Pan $\mathrm{I}^{\mathrm{A}}$ homozygotes (Additional file 2 ). To overcome this problem a new assay was developed using the KASPar SNP genotyping system and the non-synonymous substitution (Glu/Lys) present in exon 4 (G767A), which is variable only in Pan $\mathrm{I}^{\mathrm{A}}$ allelic variants [17]. Family B87, one of the two families used in the generation of the initial map [12] was determined to be polymorphic for Pan I ${ }^{\mathrm{A}}$ G767A and the Pan I locus was mapped on LG1 (Figure 1; Additional files 1 and 2) using that family.

\section{The addition of family B30 allowed new SNPs to be mapped onto the CGP map}

The new map, resulted from the addition of family B30, and of Pan I and Hb loci, contains 1046 mapped SNPs, an increase of 122 SNPs when compared to the genetic linkage map reported earlier by Hubert et al. 2010 [12]. This map was generated by the first round of calculations of the regression mapping algorithm and the positions of all loci were statistically strongly supported [21]. Another map, produced by the third round of mapping calculations [21] integrates 1300 SNPs, which represents a contribution of 376 new SNPs that could be mapped (Additional file 3). This map was generated to obtain a general idea of where poorer fitting loci reside on the genetic linkage map [21].

\section{Linkage group correspondence between maps produced by independent research groups}

Finally, we aimed to merge the CGP genetic linkage map data (this paper and Hubert et al. [12]) with the genetic linkage map data produced by a different group [14]. To identify sequences that were mapped by both, CGP (this paper and Hubert et al. [12]) and Moen et al. [14] we performed a Blastn search of an in-house made database containing the ESTs listed by Moen et al. [14] using 124 nucleotides long CGP SNP-containing sequences. EST sequence data used by Moen et al. was retrieved from GenBank using the GenBank accession numbers listed by this group [14]. Using this approach we identified 29 shared SNPs distributed on 10 different linkage groups (Additional file 4). The minimal overlap between the linkage map produced in the present study and that of Moen et al. [14] might result from ascertainment bias caused by different frequencies of SNPs in NE and NW Atlantic populations of cod and/or because CGP sequenced the 3' ends of ESTs to identify SNPs [11,12] whereas Moen et al. $[13,14]$ sequenced the 5' ends of their ESTs to detect polymorphisms.

\section{Conclusions}

The genetic linkage map presented here, that includes the marker PanI and multiple $\mathrm{Hb}$ loci, represents a useful resource for studying genotype-phenotype relationships, for QTL studies, as well as for population studies. Our 


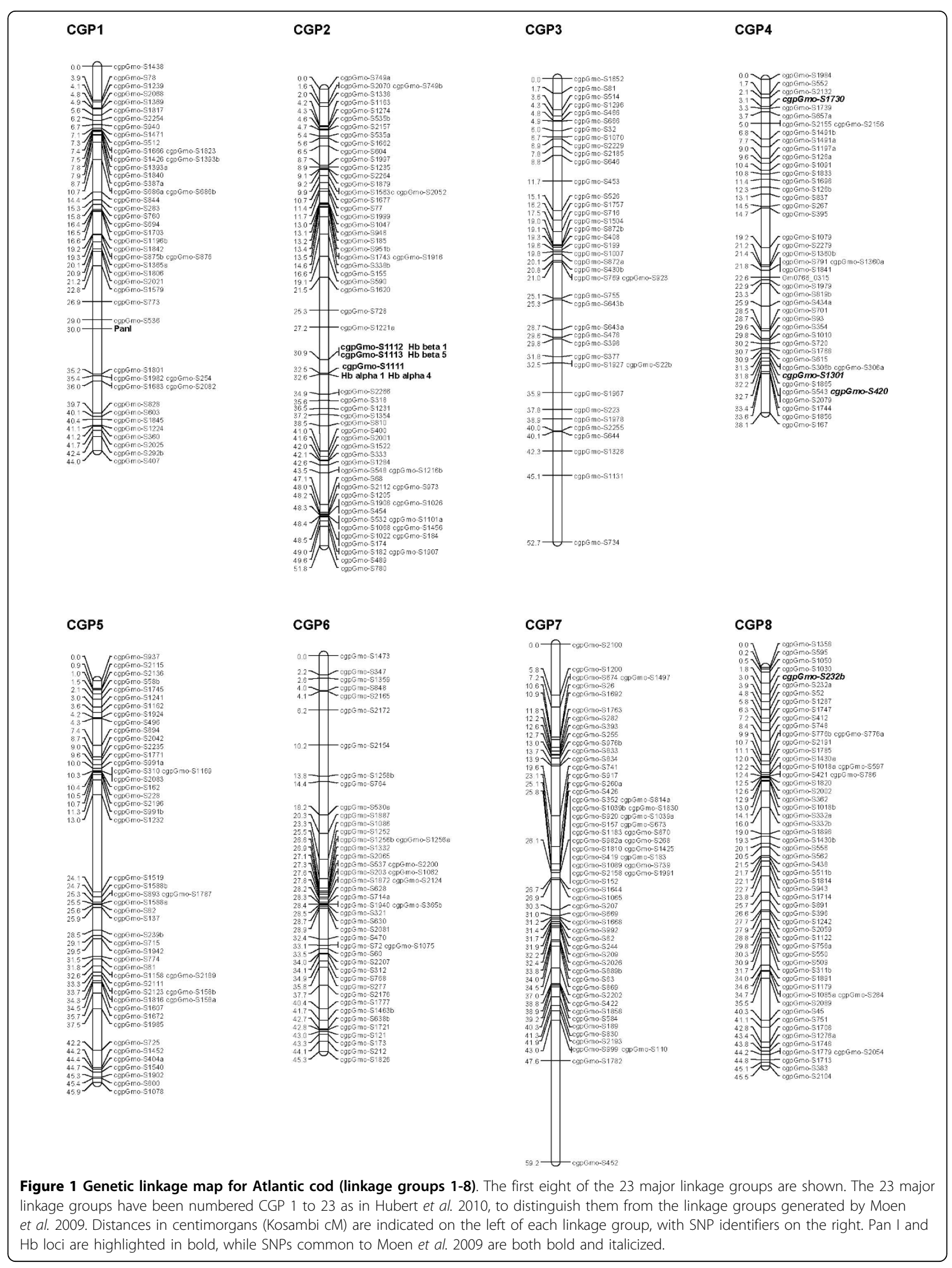




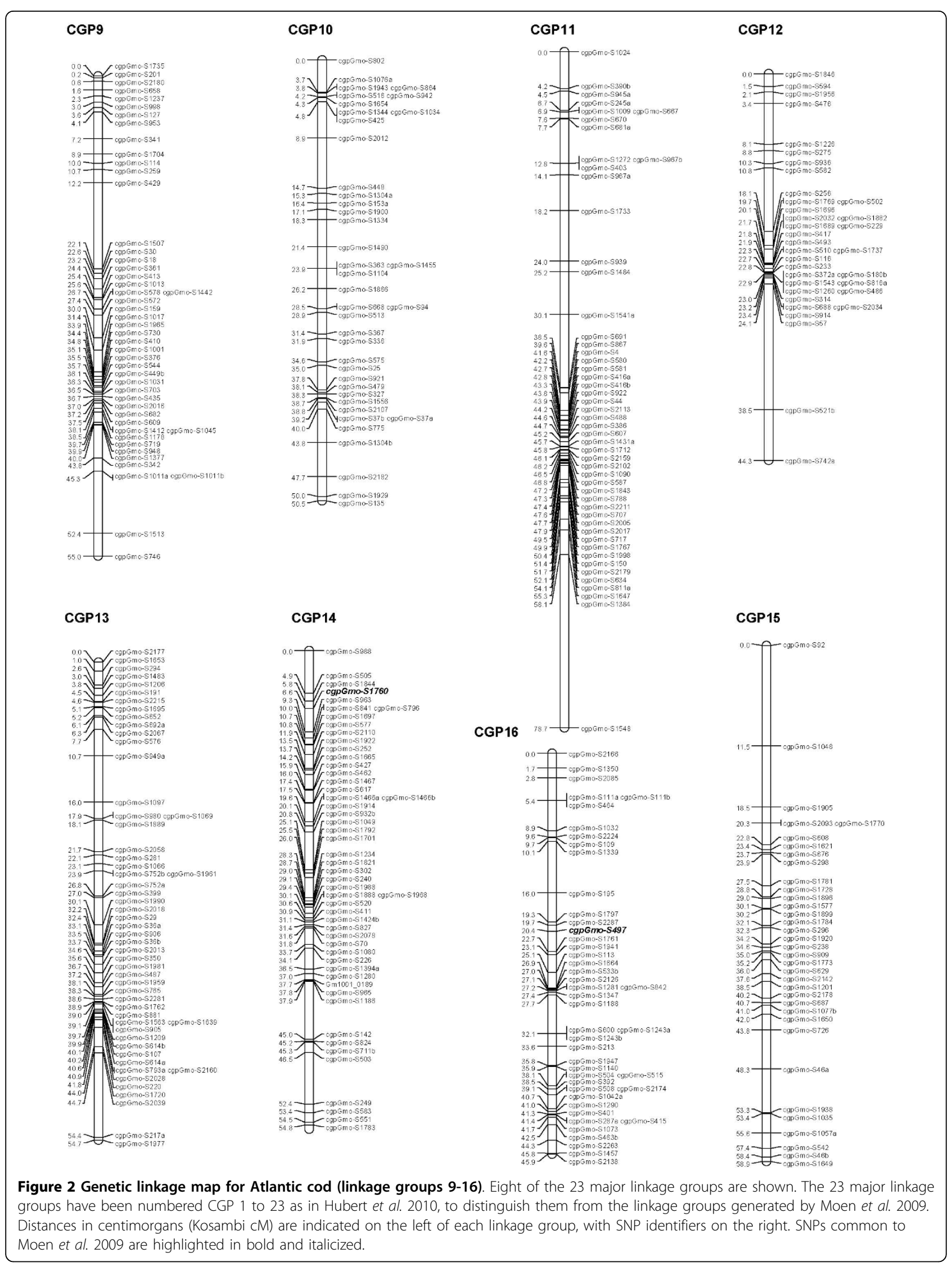




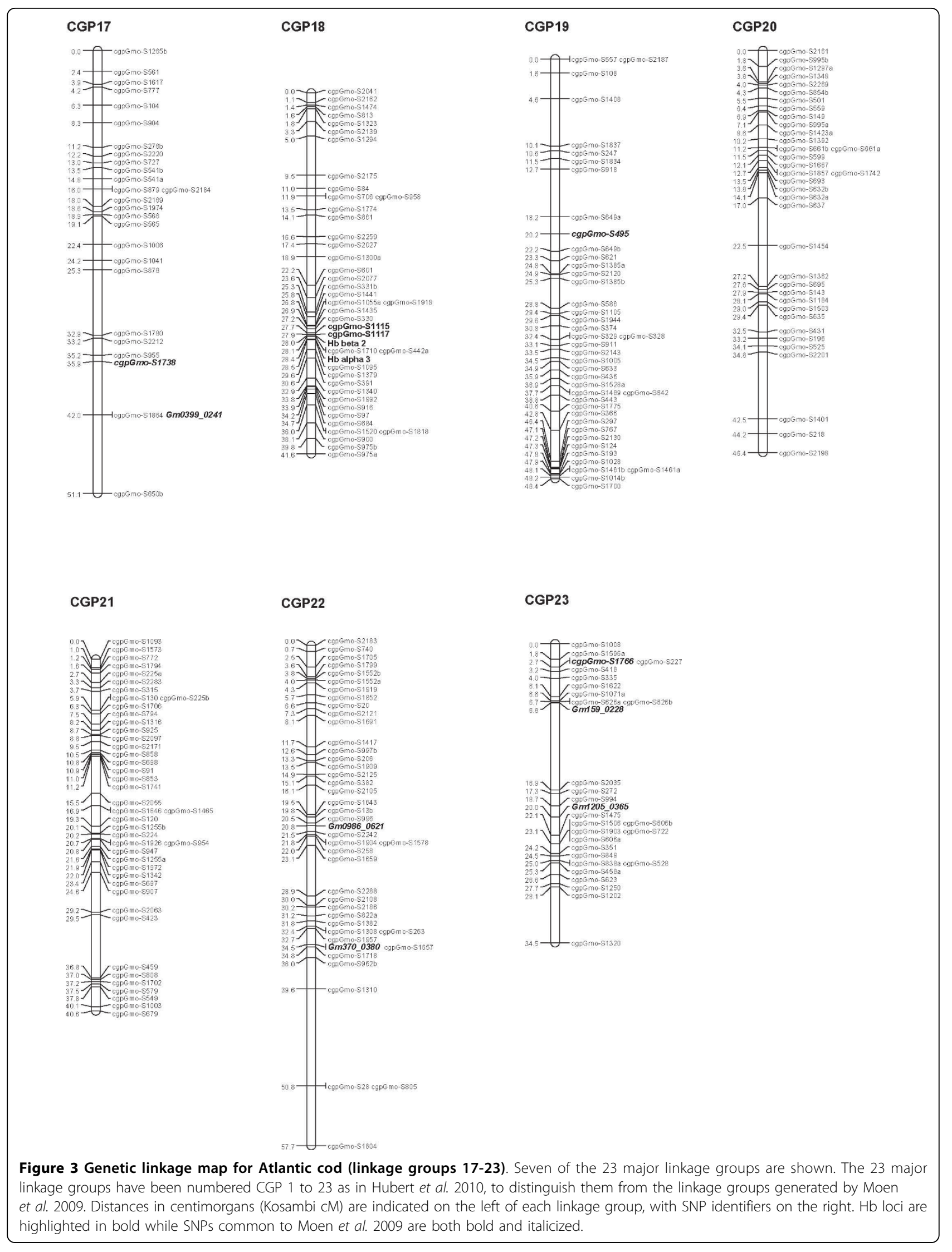


data indicate that $\mathrm{Hb}$ genes are located on two different linkage groups while Pan I locus was mapped on a third linkage group. Further studies are needed to elucidate which of these genes/linkage groups will correlate with phenotypic traits. The $\mathrm{Hb} \beta 1$ gene, which has been linked to variation in haemoglobin oxygen binding capacity and water temperature preference $[15,28]$ (although the role of this gene in temperature adaptation is still subject to debate [16]) was mapped on LG 2. New avenues for physiological and biochemical studies related to temperature and hypoxia tolerance in Atlantic cod and other fishes may result if, through further studies, it can be demonstrated that this gene is associated with relevant QTL.

\section{Additional material}

Additional file 1: Properties of the SNPs for which GoldenGate or KASPar functional assay was developed. This file includes SNP locus name, SNP accession number, position on the linkage group, sequence information regarding the SNP and the flanking regions, SNP annotation and the results of the tests for departure from Mendelian segregation.

Additional file 2: Primer sequence used for the KASPar SNP genotyping system and details regarding the SNPs used to map $\mathrm{Hb}$ $\boldsymbol{\beta} 1$ and Pan I. This file contains the list of primers designed for the KASPar SNP genotyping system, and the genotyping results obtained by screening several Atlantic cod populations with the $\mathrm{Hb} \beta 1$ and Panl SNPs used in the mapping process.

Additional file 3: Genetic linkage map with forced additional loci. This file contains the genetic linkage map with forced additional loci. The 23 major linkage groups have been numbered CGP 1 to 23 as in Hubert et al. 2010, to distinguish them from the linkage groups generated by Moen et al. 2009. Distances in centimorgans (Kosambi cM) are indicated on the left of each linkage group, with SNP identifiers on the right. Panl and $\mathrm{Hb}$ loci are in bold, italicized and highlighted in red while SNPs common to Moen et al. 2009 are in bold and highlighted in red.

Additional file 4: Linkage group correspondence between the genetic linkage groups presented in this study and Moen et al. 2009. This file contains the data related to the linkage group correspondence between the genetic linkage groups presented in this study and Moen et al. 2009.

\section{Acknowledgements}

This study was supported by Genome Canada, Genome Atlantic, and the Atlantic Canada Opportunities Agency through the Atlantic Cod Genomics and Broodstock Development Project and through an NSERC Discovery grant to SB. A complete list of supporting partners can be found at http:// www.codgene.ca/partners.php.

\section{Authors' contributions}

TB initiated the analysis of family B30 using the GoldenGate panel and the KASPar SNP genotyping system, selected SNPs for the mapping of Panl and $\mathrm{Hb}$ loci, generated the genetic linkage map and wrote the paper. $\mathrm{BH}$ wrote custom Perl scripts which were used for analysis of the data generated from the GoldenGate panel, and performed SNP analysis using the KASPar SNP genotyping system. GS performed SNP analysis using the KASPar SNP genotyping system. SB was responsible for the conceptualization, design and implementation of the SNP identification and analysis program and edited the final versions of the manuscript. All authors read and approved the final manuscript.

\section{Competing interests}

The authors declare that they have no competing interests.
Received: 21 June 2010 Accepted: 15 October 2010

Published: 15 October 2010

\section{References}

1. Rosenlund G, Skretting M: Worldwide status and perspective on gadoid culture. ICES J Mar Sci 2006, 63(2):194-197.

2. Imsland AK, Jonsdottir ODB: Linking population genetics and growth properties of Atlantic cod. Reviews in Fish Biology and Fisheries 2003, 13:1-26.

3. Sarvas TH, Fevolden SE: Pantophysin (Pan I) locus divergence between inshore v. offshore and northern v. southern populations of Atlantic cod in the north-east Atlantic. Journal of Fish Biology 2005, 67:444-469.

4. Imsland AK, Foss A, Naevdal G, Johansen T, Folkvord A, Stefansson SO, Jonassen TM: Variations in growth in haemoglobin genotypes of Atlantic cod. Fish Physiol Biochem 2004, 30(1):47-55.

5. Petersen MF, Steffensen JF: Preferred temperature of juvenile Atlantic cod Gadus morhua with different haemoglobin genotypes at normoxia and moderate hypoxia. J Exp Biol 2003, 206(Pt 2):359-364.

6. Mork J, Giskeødegård R, Sundnes G: Haemoglobin polymorphism in Gadus morhua: genotypic differences in maturing age and within-season gonad maturation. Helgolander Meeresunters 1983, 36:313-322.

7. Mork J, Giskeødegård R, Sundnes G: Population genetic studies in cod (Gadus morhua L.) by means of the haemoglobin polymorphism; observations in a Norwegian coastal population. Fiskeridir Skr (Havundersøkelser) 1984, 17:449-471.

8. Jónsdóttir ÓDB, Imsland AK, Danílsdóttir AK, Marteinsdóttir G: Genetic heterogeneity and growth properties of different genotypes of Atlantic cod (Gadus morhua L.) at two spawning sites off south Iceland. Fish Res 2002, 55:37-47.

9. Case RAJ, Hutchinson WF, Hauser L, Van Oosterhout C, Carvalho GR: Macroand micro-geographic variation in pantophysin (Panl) allele frequencies in NE Atlantic cod Gadus morhua. Marine Ecology Progress Series 2005, , 301: 267-278.

10. Pampoulie C, Jakobsdottir KB, Marteinsdottir G, Thorsteinsson V: Are vertical behaviour patterns related to the pantophysin locus in the Atlantic cod (Gadus morhua L.)? Behav Genet 2008, 38(1):76-81.

11. Bowman S, Hubert S, Higgins B, Stone C, Kimball J, Borza T, Bussey JT, Simpson G, Kozera C, Curtis BA, et al: An integrated approach to gene discovery and marker development in Atlantic cod (Gadus morhua). Mar Biotechnol (NY) 2010

12. Hubert S, Higgins B, Borza T, Bowman S: Development of a SNP resource and a genetic linkage map for Atlantic cod (Gadus morhua). BMC Genomics 2010, 11:191

13. Moen T, Hayes B, Nilsen F, Delghandi M, Fjalestad KT, Fevolden SE, Berg PR, Lien S: Identification and characterisation of novel SNP markers in Atlantic cod: evidence for directional selection. BMC Genet 2008, 9:18.

14. Moen T, Delghandi M, Wesmajervi MS, Westgaard Jl, Fjalestad KT: A SNP/ microsatellite genetic linkage map of the Atlantic cod (Gadus morhua). Anim Genet 2009, 40(6):993-996.

15. Andersen O, Wetten OF, De Rosa MC, Andre C, Carelli Alinovi C, Colafranceschi M, Brix O, Colosimo A: Haemoglobin polymorphisms affect the oxygen-binding properties in Atlantic cod populations. $P$ Roy Soc $B$ Biol Sci 2009, 276(1658):833-841.

16. Borza T, Stone C, Gamperl AK, Bowman S: Atlantic cod (Gadus morhua) hemoglobin genes: multiplicity and polymorphism. BMC Genet 2009, 10:51

17. Pogson GH: Nucleotide polymorphism and natural selection at the pantophysin (Pan I) locus in the Atlantic cod, Gadus morhua (L.). Genetics 2001, 157(1):317-330

18. Pogson GH, Fevolden SE: Natural selection and the genetic differentiation of coastal and Arctic populations of the Atlantic cod in northern Norway: a test involving nucleotide sequence variation at the pantophysin (Pan) locus. Molecular Ecology 2003, 12(1):63-74.

19. Sick K: Haemoglobin polymorphism of cod in the North Sea and the North Atlantic Ocean. Hereditas 1965, 54(1):49-69.

20. Jamieson A, Birley AJ: The demography of a haemoglobin polymorphism in the Atlantic cod, Gadus morhua L. Journal of Fish Biology 1989, 35(sa):193-204

21. Van Ooijen JW: JoinMap ${ }^{\oplus} 4$. Software for the calculation of genetic linkage maps in experimental populations. Wageningen, Netherlands: Kyazma B.V 2006. 
22. Fan Z, Fox DP: Robertsonian polymorphism in plaice, Pleuronectes platessa L., and cod, Gadus morhua L., (Pisces Pleuronectiformes and Gadiformes). Journal of Fish Biology 1991, 38:635-640.

23. Halldorsdottir $\mathrm{K}$, Arnason E: Organization of a beta and alpha globin gene set in the teleost Atlantic cod, Gadus morhua. Biochem Genet 2009, 47(11-12):817-830.

24. Halldorsdottir K, Arnason E: Multiple linked beta and alpha globin genes in Atlantic cod: a PCR based strategy of genomic exploration. Marine Genomics 2009, 2:169-181.

25. Maruyama K, Yasumasu S, Naruse K, Mitani H, Shima A, luchi I: Genomic organization and developmental expression of globin genes in the teleost Oryzias latipes. Gene 2004, 335:89-100.

26. Gillemans N, McMorrow T, Tewari R, Wai AW, Burgtorf C, Drabek D, Ventress $N$, Langeveld A, Higgs D, Tan-Un K, et al: Functional and comparative analysis of globin loci in pufferfish and humans. Blood 2003, 101(7):2842-2849.

27. Fevolden SE, Pogson GH: Genetic divergence at the synaptophysin (Syp I) locus among Norwegian coastal and north-east Arctic populations of Atlantic cod. Journal of Fish Biology 1997, 51(5):895-908.

28. Colafranceschi M, Giuliani A, Andersen O, Brix O, De Rosa MC, Giardina B, Colosimo A: Hydrophobicity Patterns and Biological Adaptation: An Exemplary Case from Fish Hemoglobins. OMICS 2010.

doi:10.1186/1756-0500-3-261

Cite this article as: Borza et al:: Integrating the markers Pan I and haemoglobin with the genetic linkage map of Atlantic cod (Gadus morhua). BMC Research Notes 2010 3:261.

\section{Submit your next manuscript to BioMed Central and take full advantage of:}

- Convenient online submission

- Thorough peer review

- No space constraints or color figure charges

- Immediate publication on acceptance

- Inclusion in PubMed, CAS, Scopus and Google Scholar

- Research which is freely available for redistribution

Submit your manuscript at www.biomedcentral.com/submit 